\title{
E-selectin Measurement
}

National Cancer Institute

\section{Source}

National Cancer Institute. E-selectin Measurement. NCI Thesaurus. Code C154736.

The determination of the amount of E-selectin present in a sample. 